\title{
O impacto da transformação digital na institucionalização de metodologias ágeis
}

\author{
Willian T. Kimura ${ }^{1}$, Flávio Horita ${ }^{1}$, Vladimir Rocha ${ }^{1}$ \\ ${ }^{1}$ Centro de Matemática, Computação e Cognição (CMCC) \\ Universidade Federal do ABC (UFABC) \\ Av. dos Estados, 5001 - Bangú 09210-580 Santo André - SP - Brazil \\ teruya.kimuradaluno.ufabc.edu.br \\ \{flavio.horita, vladimir.rocha\}eufabc.edu.br
}

\begin{abstract}
Agile methodologies have been a huge tendency in software development teams. This is due to their unique characteristics, which apply agility in the processes, avoiding too much loss in the product quality. In this context, this paper describes an analysis of how digital transformation tools influence in institutionalizing these methodologies.
\end{abstract}

Resumo. Metodologias ágeis têm tido uma relevância muito alta em empresas que trabalham com desenvolvimento de software. Isto por conta de suas características únicas que implicam agilidade nos processos, evitando perdas significativas na qualidade do produto. Neste sentido, este artigo analisa como as ferramentas de transformação digital atuam como meio para a institucionalização de tais metodologias.

\section{Introdução}

As metodologias ágeis trazem resultados positivos sobre a produtividade durante a execução de projetos nas organizações [Beck et al. 2001]. Como forma de aprimoramento e incentivo às práticas destas metodologias, ferramentas como o Jira, Trello ou o Team Foundation Server (TFS) aparecem como um potencial fator influente para apoiar a gestão dos projetos.

No âmbito da transformação digital, levanta-se então o questionamento sobre o quão impactante essas ferramentas são para a institucionalização das metodologias ágeis. Este trabalho investiga esta questão a partir da definição de um modelo conceitual, fundamentado na literatura, e de sua avaliação, por meio de um estudo quantitativo baseado em questionários.

\section{Transformação Digital como um agente para Metodologias Ágeis}

A transformação digital tem sido definida como "as mudanças agregadas pelas tecnologias digitais nos modelos de negócios das organizações" [Henriette et al. 2015]. Aplicações dessa transformação vêm sendo estudadas para compreender seu impacto em diversas áreas, tais como o Digital Market [Henriette et al. 2015].

No que tange às equipes de desenvolvimento de software, metodologias ágeis (e.g., SCRUM [Schwaber and Beedle 2002]) são modelos de desenvolvimento de projetos baseados nos valores do Manifesto Ágil [Beck et al. 2001]. Em geral, elas buscam realizar entregas constante de produtos com maior agilidade, dando maior ênfase 
a comunicação com o cliente e resposta a mudanças instantâneas. Nestas equipes, as tecnologias digitais para a gestão de projetos (e.g., Jira e Trello) têm contribuido não apenas no desempenho, mas também na compreensão dos conceitos inerentes as metodologias ágeis. Isso porque estas tecnologias implementam suas terminologias, artefatos e cerimónias. Desta forma, seu uso torna-se um meio importante para transformar e viabilizar as interações a institucionalização das metodologias ágeis, bem como facilitar seu aprendizado.

\section{Modelo Conceitual}

A Figura 1, apresenta o modelo com os dez elementos atrelados ao contexto de estudo, bem como o interrelacionamento entre eles. Estes elementos foram identificados com base na literatura existente na área [Azizyan et al. 2011, Tomás 2009, Hwang and Colyvas 2011].

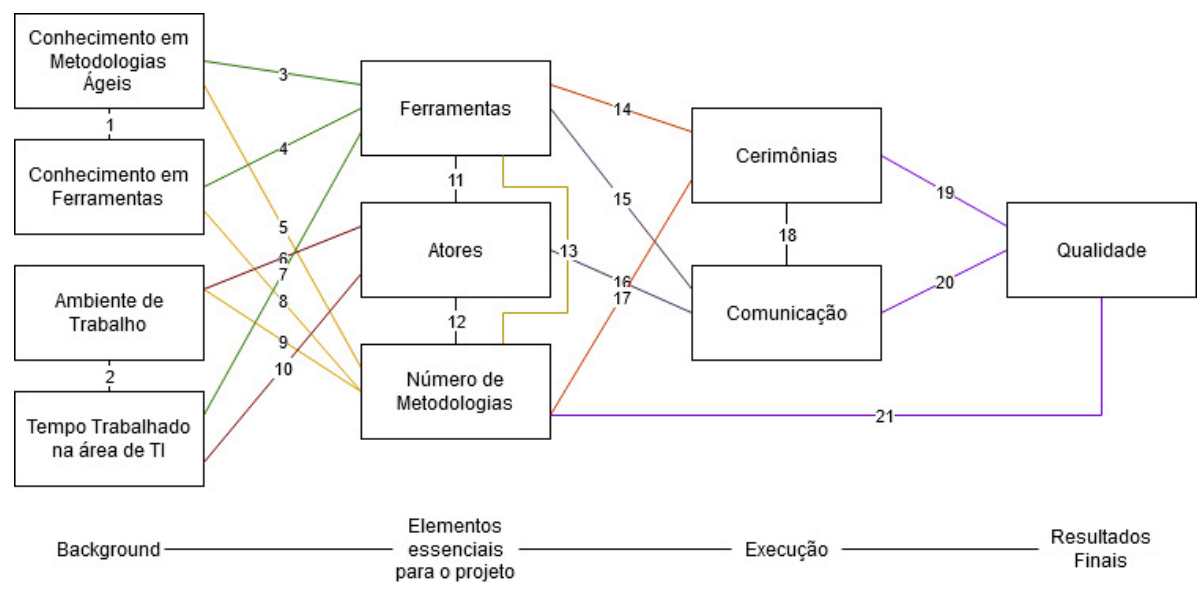

Figura 1. Modelo conceitual (Fonte: Os autores).

\subsection{Elementos Conceituais}

Por conta da limitação de espaço neste artigo, dentre os dez elementos do modelo conceitual, dois deles são detalhados a seguir. A listagem completa pode ser encontrada em: https://bit.1y/3cjbqcz.

1. Agile Method Knowledge (conhecimento em metodologias ágeis): Verifica se os atores possuem algum conhecimento prévio com metodologias ágeis como o SCRUM, Kanban, FDD, etc.

2. Working time at IT (tempo trabalhando na áreade de TI): Verifica o tempo em que a pessoa trabalhou na área de TI.

\subsection{Hipóteses}

A partir dos elementos conceituais, foi elaborado um conjunto de hipóteses para testar o relacionamento entre os elementos do modelo e, assim, analisar o modelo conceitual como um todo. Para isso, cada aresta do modelo serviu como base para a definição da hipótese. Ao todo são 21 hipóteses, das quais duas delas são apresentadas abaixo. Novamente, por limitação de espaço no artigo, a listagem completa foi disponibilizada em: https://bit.ly/3cnSNEc. 
- H6: O ambiente de trabalho e a cultura organizacional afetam o perfil dos atores envolvidos no projeto.

- H7: A quantidade de tempo que se trabalha em TI dificulta a adoção de novas ferramentas.

- H8: O conhecimento e uso de ferramentas de suporte como Jira aumenta a abertura na institucionalização demais de uma metodologiaágil (Aresta 8 da Figura 1).

- H11: As ferramentas de suporte como Jiramelhoram a organização ao do trabalho, incentivando o uso de metodologias ágeis pelos atores (Aresta 11 da Figura 1).

\section{Materiais e Métodos}

As hipóteses serviram como base para a elaboração de um questionário onde cada uma delas foi investigada adotando a Escala Likert 5-pontos (i.e., 1 - discordo completamente, 2 - discordo parcialmente, 3 - não concordo, nem discordo, 4 - concordo parcialmente e 5 - concordo completamente). A estrutura deste questionário consiste em duas partes: 1) o uso de perguntas abertas para levantar o perfil do voluntário (e.g., ramo de trabalho); e 2) o uso de perguntas fechadas para avaliar as hipóteses levantas com base na escala Likert.

O questionário foi implementado na plataforma GoogleForms e distribuído nas redes sociais, em especial, no LinkedIn, e em listas de e-mails da Sociedade Brasileira de Computação (SBC) no período entre Setembro e Novembro de 2019. Ao final do período, 63 respostas foram obtidas no questionário.

\section{Resultados}

Com base nos resultados obtidos, dois gráficos foram gerados para analisar os resultados. O Boxplot (Figura 2a) permite verificar e entender a concentração de respostas dos voluntários. Enquanto, o Intervalo (Figura 2b) permite calcular a média e, por meio deste valor, observar a tendência de cada hipótese levantada dentro da escala Likert.

A análise dos gráficos permite inferir que há maior adesão das hipótese 6 (h6) e 8 (h8) pelos participantes do questionário, visto que grande parte concorda fortemente com as afirmações relacionadas às duas. Isto é evidenciado pelo Boxplot, em que existe uma grande concentração das respostas mais próximas ao índice 5 (Figura 2a), e no gráfico de Intervalo (Figura 2b), no qual, desconsiderando o desvio padrão, possui um valor médio mais próximo do índice 5 .

Em contrapartida, as hipóteses 7 (h7) e 11 (h11), principalmente, no gráfico de Boxplot (Figura 2a), apresentam uma distribuição de ambos concentrada entre os índices 2 e 4 o que pode indicar uma fraca relevância das hipóteses para os participantes. O mesmo ocorre no gráfico de Intervalo (Figura $2 b$ ) que também indica uma baixa significância da hipótese 7 (h7), visto que seu intervalo se encontra próximo ao índice 3. Enquanto, no caso da hipótese 11 (h11), seu intervalo converge para o índice 2, mostrando baixa relevância das respostas coletadas.

Em relação às outras hipóteses, existe uma tendência no intervalo entre 4 e 5 no gráfico Boxplot (Figura 2a). Já no gráfico de Intervalo (Figura 2b), os valores médios do peso das respostas inclinam-se, em sua maioria, ao índice 4. A partir disso, é possível afirmar que as hipóteses são importantes para a compreensão do questionamento mencionado na introdução. 


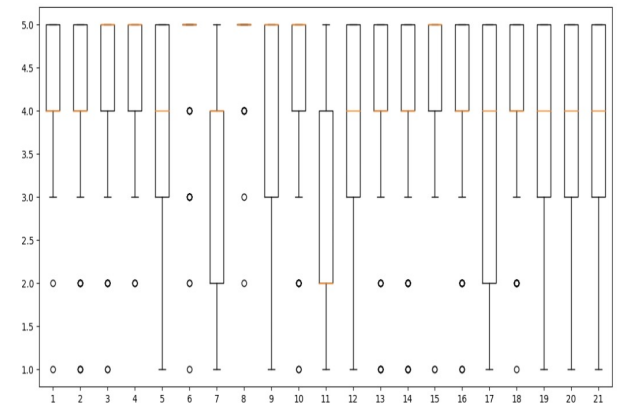

(a) Gráfico Boxplot

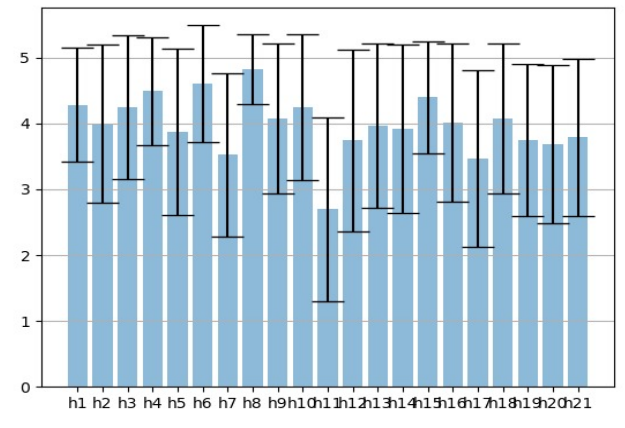

(b) Gráfico de Intervalo

Figura 2. Gráficos gerados a partir das respostas do questionário

\section{Discussões e Conclusão}

Analisando os dados obtidos pelo questionário e comparando-os com as hipóteses levantados pelas arestas do modelo conceitual, observa-se que atores com maior tempo de experiência na área de TI tem maior dificuldade em adotar novas ferramentas de tecnologia, fator que dificulta a transformação digital e a institucionalização de metodologias ágeis. É importante ressaltar que a estrutura do ambiente de trabalho e sua cultura organizacional influenciam nos perfis dos atores. Além disso, embora o conhecimento e o uso das ferramentas aumentam a abertura na instituicionalização de metodologias ágeis, os resultados também mostram que as ferramentas, por si só, não incentivam o uso de metodologias ágeis.

Como trabalho futuro, pretende-se verificar como a estrutura de trabalho impacta a adoção da transformação digital no âmbito da institucionalização das metodologias ágeis.

\section{Agradecimentos}

Os autores agradecem ao apoio financeiro do Conselho Nacional de Desenvolvimento Científico e Tecnológico (CNPq), Processo Nro 437937/2018-6.

\section{Referências}

Azizyan, G., Magarian, M. K., and Kajko-Matsson, M. (2011). Survey of agile tool usage and needs. In 2011 Agile Conference, pages 29-38. IEEE.

Beck, K., Beedle, M., Van Bennekum, A., Cockburn, A., Cunningham, W., Fowler, M., and Kern, J. (2001). Manifesto for agile software development.

Henriette, E., Feki, M., and Boughzala, I. (2015). The shape of digital transformation: a systematic literature review. MCIS 2015 Proceedings, pages 431-443.

Hwang, H. and Colyvas, J. A. (2011). Problematizing actors and institutions in institutional work. Journal of Management Inquiry, 20(1):62-66.

Schwaber, K. and Beedle, M. (2002). Agile software development with Scrum, volume 1. Prentice Hall Upper Saddle River.

Tomás, M. R. (2009). Métodos ágeis: características, pontos fortes e fracos e possibilidades de aplicação. 